\title{
The role of trace elements in the pathogenesis and progress of epileptic seizures
}

\author{
J. Chwiej ${ }^{1}$, Z. Setkowicz ${ }^{2}$, W. Winiarski ${ }^{1}$, S. Wojcik ${ }^{1}$, M. Ciarach ${ }^{2}$, Z. Stegowski ${ }^{1}$, M. Lankosz ${ }^{1}$, \\ K. Janeczko ${ }^{2}$, K. Rickers ${ }^{3}$ \\ 'Department of Applied Nuclear Physics, Faculty of Physics and Applied Computer Science, AGH-University of Science \\ and Technology, Cracow, Poland \\ ${ }^{2}$ Department of Neuroanatomy, Institute of Zoology, Jagiellonian University, Cracow, Poland \\ ${ }^{3}$ Hamburger Synchrotronstrahlungslabor HASYLAB at DESY, Hamburg, Germany
}

Epilepsy, the third most common neurological disorder, is characterized by recurrent unprovoked seizures. Although the mechanisms of epileptic convulsions have been a subject of intensive investigations for many years in most cases the etiology of the disease is not known [1].

Metallic elements participating in the processes like: oxidative stress, excitotoxicity, mitochondrial dysfunction or protein aggregation may lead to the atrophy and death of neurons in case of some neurodegenerative disorders [2-4]. Because epileptic seizures induce neurodegeneration in selected areas of brain it is suspected that metals may be involved in the pathogenesis and progress of epilepsy as well [5].

Existing evidence suggests that epileptic seizures significantly change metabolism and distribution of trace elements in the nervous tissue [6-8]. From the other hand, content of metals determinates susceptibility to convulsions [9].

In our experiment we used pilocarpine in order to induce epilepsy in rats. In order to find what elements are involved in the pathogenesis and progress of epileptic convulsions the comparison between pilocarpine treated and control rats was done. The samples of rat brain were cut using a cryomicrotome into $15 \mu \mathrm{m}$ thick slices. Thin tissue sections were mounted on Ultralene foil and freeze-dried.

X-ray fluorescence microscopy was employed for topographic and quantitative analysis of selected metals in the areas of brain tissue involved in epilepsy. The measurements were done on the bending magnet beamline L at HASYLAB. The multilayer monochromator was applied and the primary photon energy was set to $17 \mathrm{keV}$. The beam was focused with polycapillary optics for a final beam spot dimension of $15 \mu \mathrm{m} \times 15 \mu \mathrm{m}$. The characteristic X-ray lines were measured using the Vortex SDD detector from SII Nano Technology USA inc. and the time of spectra acquisition was equal to $6 \mathrm{~s}$ per pixel. Measurements of NIST standard reference materials (SRM 1833 and SRM 1832) were performed for spectrometer calibration.

The elements such us $\mathrm{P}, \mathrm{S}, \mathrm{Cl}, \mathrm{K}, \mathrm{Ca}, \mathrm{Fe}, \mathrm{Cu}, \mathrm{Zn}, \mathrm{Br}, \mathrm{Rb}$ and $\mathrm{Sr}$ were detected in rat brain sections. For each sample two-dimensional analysis of elemental distribution was performed for the area of hippocampus and brain cortex. The results of such analysis for selected control and epileptic sample were shown in Figures 1 and 2 respectively.

For four regions of hippacampus formation (CA1 - Cornu Ammonis, CA3, DG - Dentate Gyrus and $\mathrm{H}$ - Hilus) and motor cortex the mean masses per unit area were evaluated. The areas taken into account in calculations were equal to $300 \mu \mathrm{m}$ per $300 \mu \mathrm{m}$. The preliminary results showed that the level of Ca tends to be higher for CA1 region of hippocampus and cortex in case of animals with pilocarpine induced epilepsy. The opposite relation was observed for Zn level in the area of DG. 

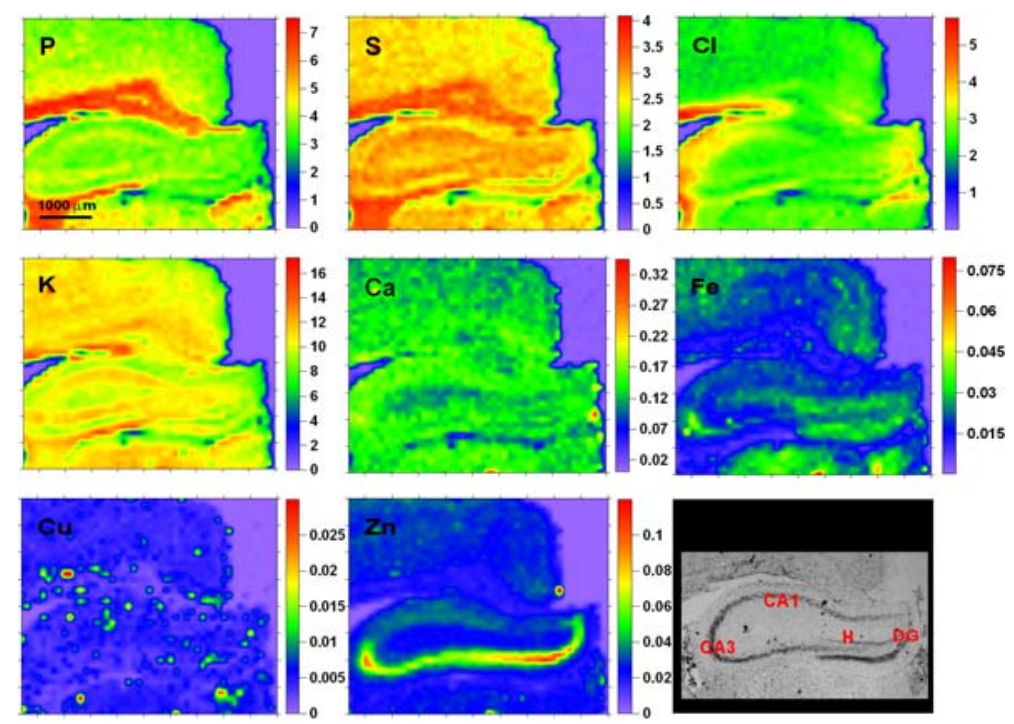

Fig. 1. Two-dimensional maps of selected elements distribution in control rat brain tissue in comparison with the microscopic view of the scanned area. On the scales masses per unit area in $\mu \mathrm{g} / \mathrm{cm}^{2}$.
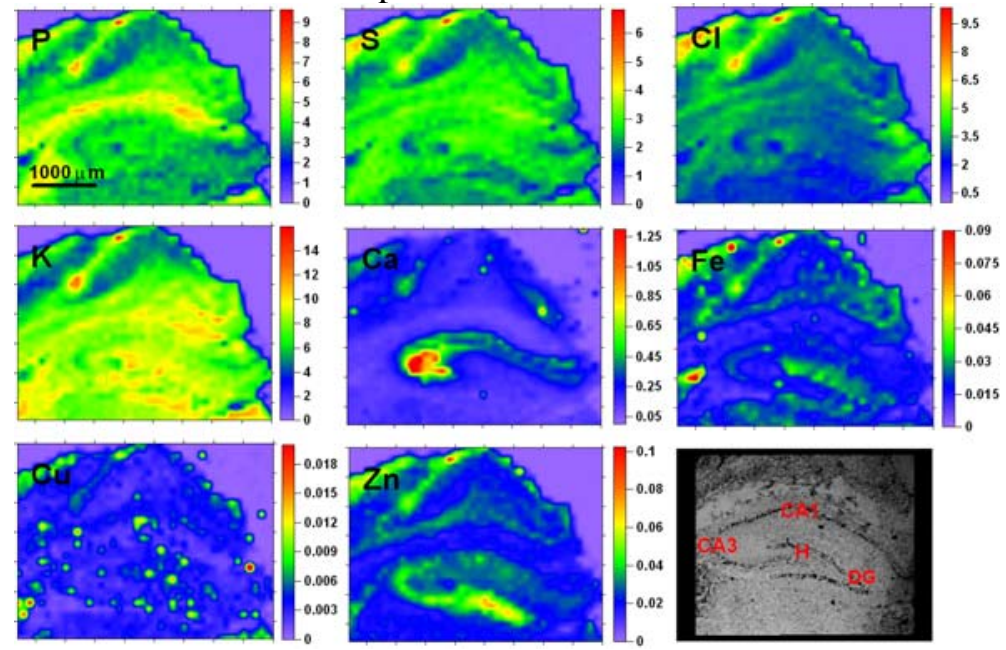

Fig. 2. Two-dimensional maps of selected elements distribution in epileptic rat brain tissue in comparison with the microscopic view of the scanned area.

\section{References:}

[1] Mello LE, Cavalheiro EA, Tan AM, Kupfer WR, Pretorius JK, Babb TL, Finch DM: Epilepsia 1993; 34: 985-995.

[2] Bush AI: Current Opinion in Chemical Biology 2000, 4: 184-191.

[3] Sayre LM, Perry G, Smith MA: Current Opinion in Chemical Biology 1999; 3: 220-225.

[4] Campbell A, Smith MA, Sayre LM, Bondy SC, Perry G: Brain Research Bulletin 2001; 55: 125132.

[5] Hamed SA, Abdellah MM: Journal of Pharmacological Sciences 2004; 96: 349-359.

[6] Papavasiliou PS, Miller ST: Experimental Neurology 1983; 82: 223-236.

[7] Carl GF, Critchfield JW, Thompson JL, McGinnis LS, Wheeler GA, Gallagher BB, Holmes GL, Hurley LS, Keen CL: Neuroscience 1989; 33: 223-227.

[8] Carl GF, Critchfield JW, Thompson JL, Holmes GL, Gallagher BB, Keen CL: Epilepsia 1990, 31: 247-252.

[9] Hirate M, Takeda A, Tamano H, Enomoto S, Oku N: Epilepsy Research 2002, 51: 109-116.

\section{Acknowledgements:}

This work was supported by the Ministry of Science and Higher education (Warsaw, Poland) and the following grants:

- The European Community-Research Infrastructure Action under FP6 "Structuring the European Research Area" Programme (through the Integrated Infrastructure Initiative "Integrating Activity on Synchrotron and Free Electron Laser Science"); Contract: RII3-CT-2004-506008.

- HASYLAB experimental grant I-20070053 EC. 